\title{
ENSAIO REFLEXIVO SOBRE A BIODIVERSIDADE E OS VALORES HUMANOS NO CONTEXTO DA PANDEMIA
}

\author{
Luzia Maria Cristina de Souza ${ }^{1}$ \\ Marina Comerlatto da Rosa² \\ Lia Maris Orth Ritter Antiqueira ${ }^{3}$
}

\begin{abstract}
Resumo: Este artigo apresenta reflexões acerca do surgimento de pandemias e a sua relação com a perda da biodiversidade, as mudanças climáticas e a exploração acelerada da natureza, que sinalizam sua situação atual de fragilidade e anunciam o esgotamento dos recursos naturais. A pandemia atualmente vivida (COVID-19) realçou também a desigualdade social e suas interfaces, impondo a necessidade de redefinição de condutas e tomada de decisões permanentes em prol do bem estar comum. A coletividade, a solidariedade e a cooperação, intra e interespecífica, devem se sobrepor ao individualismo. A discussão é elevada à relação de valores humanos e biodiversidade no contexto atual e pós-pandêmico, buscando-se vislumbrar na educação uma via para a construção epistemológica do bem viver para humanidade.
\end{abstract}

Palavras-chave: Comunidade; COVID-19; Educação Ambiental; Meio Ambiente.

Abstract: This article presents reflections on the emergence of pandemics and the relationship with the loss of biodiversity, climate change and the accelerated exploitation of nature, which signal their current fragile situation and announce the depletion of natural resources. The pandemic currently experienced (COVID-19) also highlighted social inequality and its interfaces, imposing the need to redefine conducts and make permanent decisions in favor of common welfare. The collectivity, solidarity, and cooperation, intra and interspecific, must override individualism. The discussion is elevated to the relationship of human values and biodiversity in the current and postpandemic context, seeking to envision in education a path for the epistemological construction of well live for humanity.

Keywords: Community; COVID-19; Environmental Education; Environment.

\footnotetext{
1 Universidade Tecnológica Federal do Paraná. E-mail: lummasol@yahoo.com.br Link para o Lattes: http://lattes.cnpq.br/1328435199145230

2 Universidade Tecnológica Federal do Paraná. E-mail: mcomerlattodarosa@gmail.com Link para o Lattes: http://lattes.cnpq.br/4499044859522106

${ }^{3}$ Universidade Tecnológica Federal do Paraná. Rede Paranaense de Educação Ambiental. E-mail: liaantiqueira@utfpr.edu.br Link para o Lattes: http://lattes.cnpq.br/6914975623530073
} 


\section{Introdução}

Não é novidade a concepção de que o ser humano deve exercitar o princípio de convivência mútua entre as mais diferentes formas de manifestação da vida, priorizando um relacionamento harmonioso e de respeito entre espécies. No entanto, percebe-se que isto está cada vez mais distante na realidade. A cada dia fica mais evidente o colapso ambiental advindo de ações antrópicas inconsequentes que afetam diretamente os recursos naturais e 0 planeta como um todo.

Ao analisar a ocorrência do novo Coronavírus (COVID-19), que iniciou como um surto na China e rapidamente tomou proporções mundiais, percebese a importância do papel dos valores humanos e sua relação com a biodiversidade no contexto pré e pós-pandemia. É indispensável compreender os valores ético, estético, econômico, cultural, recreativo, intelectual, científico, espiritual, emocional da biodiversidade (ALHO, 2008). E é necessário ter ciência que esta discussão contribui de forma ímpar na reorganização da sociedade, por meio de diversas frentes de atuação.

O primeiro passo neste longo processo implica na compreensão de que o surgimento de pandemias está diretamente relacionado a questões ambientais e sociais. As questões ambientais incluem a perda de biodiversidade, as mudanças climáticas, a exploração desenfreada de recursos naturais sem respeito à resiliência da Terra. Enquanto as sociais incluem as desigualdades e suas interfaces, que emergem do consumismo desenfreado e do acúmulo de renda em uma pequena parcela da sociedade.

A partir desta compreensão inicial, é necessário trabalhar a noção de que o mundo e as vidas humanas não serão mais iguais e não se deve fingir que este é um período conturbado que acabará. As consequências são permanentes e devem ser consideradas para redefinir condutas e tomar atitudes.

Propõe-se neste artigo, inserir a discussão da relação de valores humanos e biodiversidade no contexto atual e pós-pandêmico. Sem pretensão de esgotar o tema, este ensaio se justifica pela necessidade de ampliar os horizontes e contribuir com questões atuais que se julga serem fundamentais no enfrentamento à crise mundial vivida.

\section{Correlações da Biodiversidade com a Saúde}

Para se compreender a relação da biodiversidade com a saúde humana, é necessário partir de sua definição, a fim de compreender seu significado. $O$ termo "biodiversidade" é amplamente debatido na comunidade científica. Durante a Convenção da Biodiversidade - CDB (1992) foi considerada Diversidade Biológica a: 
[...] variabilidade de organismos vivos de todas as origens, compreendendo, dentre outros, os ecossistemas terrestres, marinhos e outros ecossistemas aquáticos e os complexos ecológicos de que fazem parte; compreendendo ainda a diversidade dentro de espécies, entre espécies e de ecossistemas (BRASIL, 2000, p. 09).

Para Dajoz (2005) a biodiversidade pode ser trabalhada em graus de complexidade crescente, partindo da diversidade genética, passando pela diversidade de espécies, diversidade de ecossistemas e chegando à diversidade de paisagens. Para Metzger e Cassati (2006), baseados em Redford e Richter (1999) há que se incluir na definição, toda a diversidade de organismos que habitam num espaço, compreendendo a diversidade genética, a complexidade ecológica do ambiente físico e o grande número de interações bióticas e de outros processos biológicos.

Ricklefs (2010) inclui na biodiversidade a modificação entre organismos e sistemas ecológicos em todos os níveis (variação genética, morfológica e funcional, unicidade taxonômica e endemismo), não excluindo a transformação na composição e função do ecossistema. Odum e Barrett (2013) citam a variedade de diferentes formas de vida junto com a ação ecológica que exercem no ambiente, a diversidade genética que apresentam, abrangendo o papel da paisagem e do habitat.

Estudos apontam que quanto maior a biodiversidade, menor a chance de doenças que estão presentes em animais silvestres chegarem aos seres humanos (IANNI, 2005; BARCELLOS et al. 2009; ALHO, 2012). O desmatamento e as queimadas contribuem no aumento da emissão de dióxido de carbono para a atmosfera. Os raios infravermelhos são absorvidos pelos gases liberados nas queimadas, proporcionando na atmosfera a geração de calor (efeito estufa). As mudanças climáticas, ocasionadas pela aceleração do efeito estufa, têm impacto na biodiversidade. Exemplo disso é a proliferação de insetos vetores de doenças, pois a temperatura tem aumentado gradualmente assim como os padrões de chuva (ALHO, 2012).

Acredita-se que as mudanças climáticas desempenhem um papel no surto de doenças transmitidas por insetos. Estes tendem a ser mais ativos em altas temperaturas (ALHO, 2012). Portanto, a perda de habitat promovida pelo desmatamento faz com que animais se aproximem cada vez mais dos seres humanos, então "a modificação de ecossistemas naturais torna o ambiente mais suscetível para o aparecimento de doenças" (ALHO, 2012, p. 157).

Os desastres naturais também estão intimamente relacionados à saúde coletiva, pois seus impactos incidem sobre as populações a curto, médio e longo prazo (FREITAS et al. 2014). Antigas e novas doenças, principalmente as zoonoses, são consequências inevitáveis de como as ações antrópicas estão afetando negativamente a biodiversidade. 
Com o aumento da população, da expansão urbana, da conversão da cobertura vegetal natural em pastos e extensas monoculturas, construções de hidrelétricas, introdução de espécies exóticas invasoras e demais transformações do ambiente natural ocorre o progresso da destruição de habitat. Dessa maneira, destroem-se ecossistemas naturais, que são sistemas extremamente complexos, e muitas espécies são perdidas. A perda de habitat de múltiplas maneiras está associada às mudanças climáticas, à destruição da vegetação natural, que com a queima da biomassa, libera gases do efeito estufa, dentre outras consequências.

O Brasil possui a maior biodiversidade do mundo e, consequentemente, deve ter grandes preocupações em preservá-la. No entanto, o avanço de atividades antrópicas em áreas naturais tem implicado fortemente na saúde e no bem-estar humano (ALHO, 2012). Essas implicações não ocorrem somente em território brasileiro, mas também em âmbito internacional.

A Organização Mundial da Saúde (OMS) alertava, no ano de 2016, que em torno, 12,6 milhões de pessoas foram a óbito por morarem ou trabalharem em ambiente não saudável. Assim, as doenças infecciosas também fazem parte dos problemas ambientais mundiais. A poluição do ar, da água e do solo, exposições a produtos químicos, mudanças climáticas e radiação ultravioleta contribuem para mais de 100 doenças. Perto de um quarto das mortes no mundo ocorre por fatores ambientais (OMS, 2016).

A super exploração da natureza traz crises fatais, dentre elas a perda da biodiversidade, mudanças climáticas, e nada mais atual que a pandemia de COVID-19, causada pelo SARS-CoV-2, já sendo considerada uma das mais graves crises vividas na história. A disseminação de doenças desconhecidas está ligada integralmente a destruição da natureza.

O relatório da Plataforma Intergovernamental de Políticas Científicas sobre Biodiversidade e Serviços Ecossistêmicos mostra que as alterações climáticas prejudicam os ecossistemas até a sua genética. A extinção acelerada de espécies traz inúmeros problemas para os seres humanos como um todo (JACOBI; LAUDA-RODRIGUEZ;MILZ, 2019), pois como exemplo, microrganismos que estavam presentes em animais silvestres, que foram dizimados, aparecem mais frequentemente nos seres humanos, causando doenças novas, advindas de vírus, bactérias, protozoários e fungos.

A ciência atua constantemente na busca da cura dessas doenças, com apoio de componentes químicos e princípios ativos originários da natureza. $\mathrm{O}$ potencial farmacêutico de muitas espécies de plantas, animais e microrganismos ainda é desconhecido, além disso, a medicina preventiva ainda busca na diversidade biológica novos medicamentos e produtos (ALHO, 2012). Dessa forma, vale ressaltar que a cura de muitas doenças, que já surgiram ou surgirão, pode estar na biodiversidade. Assim, ocorre uma interdependência entre a saúde do planeta e a saúde do ser humano. 
Neste ponto, a discussão assume um contexto amplo ao se considerar todos os fatores envolvidos. Autores como Boff (2015), elencam pressupostos importantes para se reverter a crise ambiental, como por exemplo, o cuidado essencial da vida sem competição, mas com o verdadeiro espírito da preocupação com o bem comum, com a civilização e com a Terra, a qual denomina de "nossa casa comum", na compreensão de que tudo que fazemos reflete no outro, na biodiversidade, no planeta. Se essa conjunção se consolida, ninguém passará despercebido, esquecido, desprezado pela indiferença corrosiva. Para o autor, deve-se entender sustentabilidade como "um modo de ser e de viver que exige alinhar as práticas humanas às potencialidades limitadas de cada bioma e às necessidades das presentes e das futuras gerações" (BOFF, 2015, p. 16).

Sendo assim, Boff (2015) afirma que a atual crise ambiental impõe uma mudança de mentalidade na educação, com a participação de educadoras(es) ambientais, que priorizem a formação de cidadãos para viver em harmonia com a natureza, estimulando os valores da compaixão, da solidariedade e da cooperação que entende a imprescindível atitude de repartir equitativamente os recursos.

\section{Valores Humanos, Biodiversidade e Pandemia: um longo caminho a percorrer}

Um resgate histórico sobre a crise ambiental permite afirmar que a discussão das questões a ela relacionadas assumiu grandes proporções durante a Rio-92, quando foram instituídas a Convenção da Diversidade Biológica, a Convenção-Quadro das Nações Unidades sobre o Clima, entre outras.

Passados quase trinta anos de discussões, ainda não foram tomadas medidas eficazes com relação à perda da biodiversidade, que ocorre como efeito das alterações climáticas, mas também do desmatamento, da caça, da poluição, da introdução de espécies exóticas e demais ações que se apresentam como grandes ameaças que afetam por conseguinte, à saúde (BARCELLOS et al. 2009). É válido ressaltar que grande parte do colapso que a biodiversidade vem sofrendo tem procedência na pressão exercida pelo ser humano (PRIMACK; RODRIGUES, 2001).

Despontando como o maior agravante da crise ambiental na atualidade, o novo Coronavírus afetou a todos de maneiras impensáveis, trazendo ameaças às diferentes formas de vida. Mostrou quanto o ser humano é despreparado para lidar com o invisível. Foi necessário criar às pressas um modus operandi para enfrentar a crise, sendo que a maioria das condutas foi adotada por imposição ou obrigação.

O isolamento social é provavelmente a maior mudança de comportamento das sociedades e traz consigo questionamentos variados e a necessidade urgente da discussão de valores e prioridades a fim de 
redesenhar a sociedade para estar preparada na volta ao que tem se chamado de "normalidade".

Mas antes é preciso significar o que levou o planeta à pandemia. Essa questão perpassa o fenômeno social ligado ao estilo de vida das sociedades, acentuado pela dimensão econômica. Passa pela discussão do menosprezo aos aspectos da vida coletiva ou individual de todos, que prioriza a dimensão econômica em detrimento das outras.

Santos (2020) alerta sobre esta questão, que deve ser utilizada como uma lição sobre a urgente necessidade de devolver ao Estado e às comunidades o poder das decisões de resposta às emergências essenciais em favor da vida, e não de sua mercantilização. Enfatiza ainda que a organização social deve articular os processos políticos e civilizatórios, a tal ponto que a sociedade humana reconheça a sua pequenez perante a natureza e, nesse entendimento, haja por meio de uma nova visão epistemológica, cultural e ideológica que amplie as vias de soluções conservadoras da vida humana com dignidade na Terra.

De acordo com Fernandes e Sampaio (2008) há uma convergência de pensamentos que reforçam a ideia de que a dualidade entre sociedade e natureza não é a única responsável pela crise socioambiental em suas várias dimensões, entretanto, antes de tudo, centrada na sociedade e no seu modo de vida. Há uma difícil relação entre o desenvolvimento econômico e a preservação da natureza, indicadas por Maturana e Varela (2001). Num mesmo alinhamento de raciocínio se encontram Morin $(2013,2017)$ e Santos (2020), quando apontam o esgotamento da materialidade contida na natureza, como uma contradição, provocada pelo próprio ser humano e pelo sistema.

É nesse sentido que Morin ${ }^{4}$ adverte para a degradação que no passando era ambiental, mas que agora é, além disso, uma degradação interior. A degradação da natureza também é degradação do mundo humano e estes são inseparáveis. A pandemia é também uma crise econômica, maior que as crises do passado, porém na qual se percebe uma progressão dos perigos. A humanidade deve caminhar a uma consciência comum de destino. A solidariedade e cooperação estão ainda muito pequenas diante dos grandes desafios que a situação impõe.

Morin $(2013,2017)$ apregoa que há uma crise de consciência dos problemas ambientais ocasionados pela humanidade, sem o reconhecimento da grande responsabilidade que as gerações atuais têm para com as futuras gerações. A humanidade está afetada em vários aspectos, mas as crises acontecem para serem superadas e para provocar mudanças e encontrar outras soluções. Essa capacidade precisou ser demonstrada no passado ao se

4Participação de Edgar Morin na Webinar "Veredas Para o Futuro: O Mundo Pós Covid-19" realizada em 05 de junho de 2020. Disponível em: https://youtu.be/qICoQPsIFlc. 
lidar com grandes guerras, convulsões políticas e outras questões ligadas à saúde.

De acordo com Morin (2013), o avanço da intoxicação consumista, o individualismo, o egocentrismo que sobrepõem a solidariedade, as enganosas desculpas que falseiam a ambição pelo lucro, as novas corrupções, as hiperespecializações que ampliam as ignorâncias, estão implícitas numa concepção de desenvolvimento que ignora a humanidade e as culturas, contida de deficiência intelectual, moral e psíquica. Contrapõem o verdadeiro desenvolvimento que demanda soluções complexas e que deve estimular todas as nações. É urgente encontrar novos rumos, sair do comodismo em prol da manutenção da vida na Terra.

Morin ${ }^{4}$ defende que a crise do planeta é também da pessoa individualmente, existencial, nacional, do planeta, do trabalho, da família, de harmonia ou conflitos e dificuldades, mas que pode ser uma evidente oportunidade para o progresso da consciência. No entanto, a mesma oportunidade pode ser um gatilho para regressão ao se considerar a minimização do poder do Estado em ajudar a coletividade e o fortalecimento do poder da privatização que vende saúde, educação, dentre outras necessidades básicas. O autor afirma, também, que a situação atual é uma advertência do agravamento dos desastres causados ao planeta. Sem manifestar pessimismo e nem otimismo, defende que é preciso reescrever a história humana com simpatia, solidariedade e luta permanente. Não se pode pensar em termos de harmonia total da humanidade, mas também não se deve abnegar esta possibilidade, unindo forças para tal empreitada. Enfatiza a necessidade da reforma do pensamento e da educação para atingir a reforma da sociedade e da vida. Aponta como caminho a solidariedade e o sentimento de pertencimento, para junção dos elementos e da vida em comunhão (MORIN, 2017).

Acredita-se que essa conscientização possa elevar o processo ensinoaprendizagem ao paradigma ecológico e à ecoeducação sustentável. Segundo Boff (2015), isso demanda transformação metodológica do ensino, imersa num trabalho empírico que valoriza e resgata os saberes, os conhecimentos, as necessidades e os problemas locais. Em que todas as "instâncias se mantenham, reformem-se, evoluam e se insiram no todo da realidade biosocioecológica" (BOFF, 2015 p.154), e revelem a sustentabilidade nesse processo, mediante uma ecoformação. $\mathrm{O}$ autor pontua que "a sustentabilidade deve ser pensada numa perspectiva global, envolvendo todo o planeta, com equidade, fazendo que o bem de uma parte não se faça à custa do prejuízo da outra" (BOFF, 2015, p. 17).

O Papa Francisco (2015) convida em sua Encíclica sobre ecologia, que compreende além do ambiental, o social, o político, o cultural, o cotidiano e o espiritual (BOFF, 2020), inspirada na invocação de São Francisco, a ouvir os gemidos da Terra, exortando todas(os) a uma "conversão ecológica", a "mudar de rumo", assumindo a responsabilidade de um compromisso para com o 
"cuidado da casa comum". O Pontífice quer entrar em diálogo com todas(os), como instrumento para enfrentar e resolver os problemas. No Cântico das Criaturas, São Francisco recorda que a terra "se pode comparar ora a uma irmã, com quem partilhamos a existência, ora a uma mãe, que nos acolhe nos seus braços" (FRANCISCO, 2015 p. 03).

Desta forma, há uma conexão entre Boff (1997) e o Papa Francisco (2015), quando preconizam o amor incondicional e libertador presente em todo o Universo e cada ser:

No Universo todos os seres existem e vivem uns pelos outros, com os outros, nos outros e para os outros. Ninguém está fora dessa relação includente. [...] É esse amor-solidariedade que constitui a grande comunidade cósmica, terrenal e humana. É ele que dá origem também ao princípio da reciprocidadecomplementaridade. Um ajuda reciprocamente o outro a existir e a se desenvolver. Todos se complementam e crescem juntos: as espécies, os ecossistemas e o inteiro Universo" (BOFF, 1997, p. 133).

De acordo com Francisco (2015), é necessário refletir sobre até onde vai a indiferença e a omissão diante dos problemas globais e o que deve ser feito para promover uma transformação de dentro para fora, através de uma autopercepção que identifique o que é vaidade e o que é hipocrisia. É preciso um olhar diferente para as consequências do desenvolvimento convencional e esforço na busca de uma força salvífica e uníssona em virtude dos famintos, doentes, estrangeiros, necessitados e descartados. Lutar contra as pobrezas espirituais e materiais.

Segundo Francisco (2015), o coração da proposta da Encíclica sobre a ecologia é a ecologia integral como novo paradigma de justiça; uma ecologia que "integre o lugar específico que o ser humano ocupa neste mundo e as suas relações com a realidade que o rodeia" (FRANCISCO, 2015, p. 14). Defende que o ser humano também é uma criatura deste mundo, que tem direito a viver e ser feliz e, além disso, possui uma dignidade especial, e, portanto, não se pode desconsiderar os efeitos nocivos do modelo atual de desenvolvimento, e da cultura do descarte sobre a vida das pessoas.

A Encíclica ressalta ainda que o planeta está em situação de emergência e colapso ambiental devido ao acentuado antropocentrismo que se vive, onde o ser humano, de acordo com (Francisco, 2015, p. 60) "se constitui um dominador absoluto" perante a natureza, esquecendo-se que tudo está integrado. Humanos teceram um desenvolvimento ilimitado, o que "supõe a mentira da disponibilidade infinita dos bens do planeta, que leva a espremê-lo até ao limite, e para além do mesmo" (FRANCISCO, 2015, p. 83). 


\section{Conclusões}

É preciso retomar o princípio de convivência mútua entre as mais diferentes formas de vida, respeitando-as e valorizando-as em sua totalidade. É também imprescindível tomar atitudes para o enfrentamento do colapso ambiental que está evidente e que deriva de ações antrópicas mal conduzidas. Nesse contexto a Educação Ambiental assume um papel de extrema relevância, onde abordará assuntos como a perda da biodiversidade e mudanças climáticas com ainda mais propriedade.

O momento histórico contribuirá se utilizado como alavanca para que os discursos se tornem concretos. A pandemia não pode ser subestimada e deve ser encarada como um desafio coletivo a todos que habitam a denominada casa comum, a Terra.

Acima de tudo, é um momento para repensar valores e progredir enquanto humanidade. O ser humano faz parte do processo de destruição. Deve estar obrigatoriamente presente na cura.

\section{Agradecimentos}

O presente trabalho foi realizado com apoio da Coordenação de Aperfeiçoamento de Pessoal de Nível Superior - Brasil (CAPES) - Código de Financiamento 001.

\section{Referências}

ALHO, C.J.R. The value of biodiversity. Brazilian Journal of biology, v.68, n. 4, 2008.

ALHO, C.J.R. Importância da biodiversidade para a saúde humana: uma perspectiva ecológica. Estudos Avançados, v. 26, n. 74, 2012.

BARCELLOS, C.; et al. Mudanças climáticas e ambientais e as doenças infecciosas: cenários e incertezas para o Brasil. Epidemiologia e Serviços de Saúde, Brasília, v. 3, n.18, p. 285-304, jul-set 2009.

BRASIL, Ministério do Meio Ambiente. Convenção sobre Diversidade Biológica: Série Biodiversidade 1. Brasília: MMA, 2000.

BOFF, L. A Águia e a Galinha. Uma metáfora da condição humana. 27a edição. Petrópolis-RJ: Vozes, 1997.

BOFF, L. Sustentabilidade: o que é: o que não é. $4^{a}$ ed. Petrópolis: Vozes, 2015.

BOFF, L. A encíclica ecológica Laudato Si. 26 de maio de 2020. Disponível em: <https://aterraeredonda.com.br/a-enciclica-ecologica-laudato-si/>. Acesso em: 26 jul. 2020. 
DAJOZ, R. Princípios de Ecologia. Porto Alegre: Artmed, 2005.

FERNANDES, V; SAMPAIO, C.A.C. Problemática ambiental ou problemática socioambiental? A natureza da relação sociedade/meio ambiente. Desenvolvimento e Meio Ambiente, Curitiba, n. 18: p. 87-94, jul/dez, 2008.

FRANCISCO, P. Carta Encíclica Laudato Si: sobre o cuidado da nossa casa comum. 2015.

Disponível em:<https://w2.vatican.va/content/dam/francesco/pdf/encyclicals/documents/pa pa-francesco 20150524 enciclica-laudato-si po.pdf>. Acesso 26 jul. 2020.

FREITAS, C.M. et al. Desastres naturais e saúde: uma análise da situação do Brasil. Ciência \& Saúde Coletiva, v. 19, n. 9, 2014.

JACOBI, P.B.; LAUDA-RODRIGUEZ, Z.L; MILZ, B. Natureza em declínio: a advertência do relatório IPBES sobre extinção de espécies. Ambiente \& Sociedade, São Paulo, v. 22, n.2, p. 1-4, 2019. Editorial.

IANNI, A.M.Z. Biodiversidade e Saúde Pública: questões para uma nova abordagem. Saúde e Sociedade, v.14, n.2, 2005.

MATURANA, H.R.; VARELA, F.J. A Árvore do Conhecimento: as bases biológicas da compreensão humana. São Paulo: Pala Athenas, 2001

METZGER, J.P.; CASSATI, L. Do diagnóstico à conservação da biodiversidade: 0 estado da arte do programa BIOTA/FAPESP. Biota Neotropica, v. 6, n. 2, maio 2006.

MORIN, E. A via para o futuro da humanidade. Tradução Edgard de Assis Carvalho e Mariza Perassi Bosco. Rio de Janeiro: Bertrand Brasil, 2013.

MORIN, E. A cabeça bem-feita: repensar a reforma, reformar o pensamento. Tradução Eloá Jacobina. 23ª ed. Rio de Janeiro: Bertrand Brasil, 2017.

ODUM, E.P.; BARRETT, G.W. Fundamentos de ecologia. São Paulo: Cengage Learning, 2013.

OMS, Organização Mundial da Saúde.10 fatos sobre a prevenção de doenças em ambientes saudáveis, março de 2016. Disponível em:<https://www.who.int/features/factfiles/environmental-disease-burden/en/> Acesso em: 26 jul. 2020.

PRIMACK, R.B.; RODRIGUES, E. Biologia da conservação. Londrina: E. Rodrigues, 2001.

RICKLEFS, R. E. Economia da Natureza. 6ª ed. Rio de Janeiro: Guanabara Koogan, 2010.

SANTOS, B.S. A Cruel Pedagogia do Vírus. Coimbra: Almedina, 2020. 